\title{
Two heads are better than one: the association between condom decision-making and condom use errors and problems
}

\author{
R Crosby, ${ }^{1,2,3}$ R Milhausen, ${ }^{3,4}$ S A Sanders, ${ }^{2,3}$ C A Graham, ${ }^{2,6}$ W L Yarber ${ }^{2,3,5}$
}

${ }^{1}$ College of Public Health at the University of Kentucky, Lexington, Kentucky, USA; ${ }^{2}$ The Kinsey Institute for Research in Sex, Gender, and Reproduction, Indiana, USA; ${ }^{3}$ Rural Center for AIDS/STD Prevention at Indiana University, Indiana, USA;

${ }^{4}$ Department of Family Relations and Applied Nutrition at the University of Guelph, Guelph, Ontario, Canada; ${ }^{5}$ Department of Applied Health Science, Indiana University, Indiana, USA;

${ }^{6}$ Oxford University, Oxford, UK

Correspondence to:

R Crosby, College of Public Health, 121 Washington Ave., Lexington, KY 40506-0003, USA; crosby@uky.edu

Accepted 29 October 2007

\section{ABSTRACT}

Objectives: This exploratory study compared the frequency of condom use errors and problems between men reporting that condom use for penile-vaginal sex was a mutual decision compared with men making the decision unilaterally.

Methods: Nearly 2000 people completed a web-based questionnaire. A sub-sample of 660 men reporting that they last used a condom for penile-vaginal sex (within the past three months) was analysed. Nine condom use errors/problems were assessed. Multivariate analyses controlled for men's age, marital status, and level of experience using condoms.

Results: Men's unilateral decision-making was associated with increased odds of removing condoms before sex ended (adjusted odds ratio (AOR) 2.51, $p=0.002$ ), breakage (AOR 3.90, $p=0.037$ ), and slippage during withdrawal (AOR 2.04, $p=0.019$ ). Men's self-reported level of experience using condoms was significantly associated with seven out of nine errors/problems, with those indicating less experience consistently reporting more errors/problems.

Conclusions: Findings suggest that female involvement in the decision to use condoms for penile-vaginal sex may be partly protective against some condom errors/ problems. Men's self-reported level of experience using condoms may be a useful indicator of the need for education designed to promote the correct use of condoms. Education programmes may benefit men by urging them to involve their female partner in condom use decisions.

The consistent and correct use of the male condom can be highly protective against the transmission of most sexually transmitted infections (STI). ${ }^{1-3}$ Unfortunately, evidence suggests that men experience multiple forms of errors and problems when using condoms. ${ }^{4-9}$ Moreover, the aetiology of these errors and problems has been under-studied. One particularly attractive hypothesis is that fewer errors and problems occur when condom use is the result of decision-making that involves the female sex partner. Past studies suggest that women are quite aware of the condom use errors and problems experienced during sex with male partners. ${ }^{4}{ }^{6}{ }^{10-13}$ In essence, it is reasonable to speculate that women may correct male errors in condom use. Accordingly, the purpose of this study was to compare the frequency of condom use errors/problems between men reporting that condom use was a mutual decision compared with men making the decision unilaterally.

\section{METHODS}

\section{Participants}

A convenience sample was recruited on the basis of an electronic mailing list for a large, internet-based sexual enhancement product company. Individuals who were over the age of 18 years, used a male condom at least once in the past three months, and were able to read English were invited to participate. Volunteers were provided with a code used to access the web-based questionnaire. This code was only valid for a single use thereby precluding any one person from completing the questionnaire multiple times. All study procedures were anonymous and approved by the Internal Review Board at the University of Windsor in Ontario, Canada. Nearly 2000 people $(\mathrm{N}=1987)$ completed the survey.

The analytical subsample for this study was comprised only of men reporting that a condom was used during the last time they engaged in penile-vaginal sex $(\mathrm{N}=704)$. Of these men, 44 reported that the female partner unilaterally decided that condoms should be used. Because the purpose of the study was to compare men making the decision on a mutual basis with men making the decision without participation from the female partner, these 44 cases were excluded, leaving 660 men in the subsample.

\section{Design and measures}

The study design provided an event-specific analysis. This is important because condom use errors are assessed for the same penile-vaginal sexual encounter used to assess whether condoms were used by mutual decision or unilaterally by men.

Three covariates were identified: age, marital status, and men's self-reported level of experience using condoms. The latter covariate was measured by asking men "How much experience would you say you have with the male condom?" Response alternatives were provided on a four-point scale ranging from "none" to "quite a lot".

Based on previous studies of condom use errors and problems, ${ }^{4-17}$ nine outcome variables were identified. These were erection loss while applying the condom and while using the condom, putting the condom on after penetration and taking it off before sex ended, breakage, slippage during sex and during withdrawal, and problems with the "fit" and with the "feel" of the condom.

\section{Data analysis}

First, bivariate associations were assessed between the key correlate (mutual versus unilateral 
Table 1 Prevalence and bivariate associations of selected condom use errors and problems with condom use decision-making (unilateral versus mutual)

\begin{tabular}{lllll}
\hline Outcome* & $\begin{array}{l}\text { \% Unilateral* } \\
(\mathbf{n}=\mathbf{1 8 8})\end{array}$ & $\begin{array}{l}\text { \% Mutual* } \\
\text { (n= 470) }\end{array}$ & PR (95\% CI) & p Value \\
\hline Lost erection while applying condom & 9.1 & 5.3 & $1.72(0.95$ to 3.11$)$ & 0.07 \\
Lost erection while using condom & 10.2 & 6.6 & $1.54(0.90$ to 2.67$)$ & 0.12 \\
Applied condom after sex began & 20.4 & 24.8 & $0.82(0.60$ to 1.14$)$ & 0.24 \\
Removed condom before sex ended & 12.8 & 5.7 & $2.24(1.33$ to 3.79$)$ & 0.002 \\
Condom broke & 3.2 & 0.8 & $3.81(1.09$ to 13.34$)$ & 0.02 \\
Condom slipped off during sex & 4.8 & 3.0 & $1.63(0.72$ to 3.70$)$ & 0.24 \\
Condom slipped off during withdrawal & 12.8 & 6.4 & $2.02(1.21$ to 3.36$)$ & 0.006 \\
Had a problem with "fit" & 11.8 & 8.7 & $1.36(0.83$ to 2.22$)$ & 0.22 \\
Had a problem with "feel" & 33.2 & 30.4 & 1.09 (0.85 to 1.39$)$ & 0.48 \\
\hline
\end{tabular}

$\mathrm{Cl}$, Confidence interval; PR, prevalence ratio.

${ }^{*}$ All measures apply only to the last time a condom was used for penile-vaginal sex.

decision-making) and the nine outcomes. Associations were assessed by prevalence ratios, their $95 \%$ confidence intervals (CI), and respective $\mathrm{p}$ values. Potential covariates were assessed statistically and two were associated with both the key correlate and at least one of the condom use errors and problems. These two were age and men's level of experience using condoms. To control for these covariates, each outcome was then tested in a separate logistic regression model using forward stepwise entry. Because the variable representing men's level of experience using condoms produced a highly skewed distribution this was dichotomised to compare those indicating "quite a lot" (73.6\%) with the remainder. The models were used to calculate adjusted odds ratios (AOR), their 95\% CI, and the corresponding $\mathrm{p}$ values.

\section{RESULTS}

\section{Characteristics of the sample}

The average age was 36.0 years (SD 9.0) with a range of 19 to 67 years. Just over one-third $(34.9 \%)$ indicated that they were not currently married. Just over one-half (53.1\%) indicated having completed at least a bachelor's degree. The median annual income interval was US\$50 000-75 000. Nearly three-quarters of the men $(73.6 \%)$ reported having "a lot" of experience using condoms. Approximately one-third (28.5\%) reported that they alone made the decision to use condoms the last time condoms were used for penile-vaginal sex, with the remaining men indicating that this was a mutual decision.

\section{Bivariate associations}

Table 1 displays the observed prevalence of the nine assessed condom use errors and problems stratified by whether condom use decisions were unilateral or mutual. Table 1 also displays results from the contingency table analyses. As shown, men making decisions unilaterally were more than twice as likely to report that condoms were removed before sex ended. Unilateral decision-makers were nearly four times more likely to report breakage and twice as likely to report slippage during withdrawal.

\section{Multivariate associations}

Table 2 displays the significant correlates from the regression models. As shown, men's unilateral decision-making retained multivariate significance with early removal of condoms, breakage, and slippage during withdrawal. Compared with men using condoms on the basis of mutual decision-making, those making the decision unilaterally were approximately 2.5 , 3.9 , and 2.0 times more likely, respectively, to report these three errors/problems. Table 2 also shows that men reporting less experience using condoms were significantly more likely than their "experienced" counterparts to report seven of the nine selected errors/problems. The exceptions to this were applying condoms after sex had begun and breakage.

\section{DISCUSSION}

In controlled, event-specific, analyses men's unilateral decisionmaking to use condoms was associated with three important condom errors/problems. The association with condom breakage is particularly important as it has not previously been investigated as a potential cause of breakage..$^{511} 1415$ Similarly, associations with early removal and slippage during withdrawal are important and represent further novel findings. That men making condom use decisions unilaterally were more likely to remove condoms early is probably a consequence of their partner's lack of interest in using condoms. Slippage during withdrawal is also relatively straightforward to explain given that female assistance in holding on to the rim during withdrawal may have been lacking as a result of their lack of investment in condom use from the beginning. Alternatively, the finding related to breakage is somewhat less intuitive. Potentially, men acting unilaterally may have made more mistakes that may culminate in breakage eg, re-using condoms, not keeping condoms well lubricated during sex, touching condoms with sharp objects.

Although the specific reasons for the observed associations warrant further research, this initial evidence provides a somewhat compelling case that female involvement in condom use decisions provides a protective effect relative to certain errors/problems. Of interest is the fact that mutual decisionmaking (ie female involvement) was not implicated as a potential cause for any of the nine errors/problems. Whether the decision was unilateral or mutual, however, was not important for the majority of the selected errors/problems, thereby suggesting that female involvement can only be beneficial but should not be viewed as a panacea when considering a broad range of errors/problems.

In the process of controlling for men's self-reported experience with the use of condoms it became apparent that this measure was indeed robust. From an intervention perspective, this single assessment may have value as a strategy to triage less experienced men for targeted education designed to reduce their frequency of condom use errors/problems. Clearly, the prevalence of errors/problems in this relatively well-educated, highincome sample of men (spanning a broad age range) was 
Table 2 Correlates achieving multivariate significance in relation to nine selected condom use errors and problems

\begin{tabular}{|c|c|c|}
\hline Outcome & $\mathrm{AOR}^{*}(95 \% \mathrm{Cl})$ & p Value \\
\hline \multicolumn{3}{|c|}{ Lost erection while applying condom } \\
\hline Older age & $1.04(1.006$ to 1.067$)$ & 0.018 \\
\hline Less condom use experience & $2.38(1.25$ to 4.56$)$ & 0.009 \\
\hline \multicolumn{3}{|l|}{ Lost erection while using condom } \\
\hline Less condom use experience & 2.87 (1.59 to 5.18$)$ & 0.0001 \\
\hline \multicolumn{3}{|l|}{ Applied condom after sex began } \\
\hline Older age & $0.96(0.94$ to 0.98$)$ & 0.001 \\
\hline \multicolumn{3}{|l|}{ Removed condom before sex ended } \\
\hline Less condom use experience & 2.49 (1.38 to 4.50$)$ & 0.003 \\
\hline Unilateral decision-making & 2.51 (1.40 to 4.50$)$ & 0.002 \\
\hline \multicolumn{3}{|l|}{ Condom broke } \\
\hline Unilateral decision-making & $3.90(1.09$ to 14.0$)$ & 0.037 \\
\hline \multicolumn{3}{|l|}{ Condom slipped off during sex } \\
\hline Less condom use experience & 2.34 (1.01 to 5.45$)$ & 0.048 \\
\hline \multicolumn{3}{|c|}{ Condom slipped off during withdrawal } \\
\hline Older age & $1.04(1.01$ to 1.07$)$ & 0.007 \\
\hline Less condom use experience & 2.77 (1.53 to 5.02$)$ & 0.001 \\
\hline Unilateral decision-making & 2.04 (1.12 to 3.69$)$ & 0.019 \\
\hline \multicolumn{3}{|l|}{ Had a problem with "fit" } \\
\hline Less condom use experience & $1.81(1.05$ to 3.13$)$ & 0.03 \\
\hline \multicolumn{3}{|l|}{ Had a problem with "feel" } \\
\hline Less condom use experience & 1.97 (1.37 to 2.85$)$ & 0.0001 \\
\hline
\end{tabular}

$\mathrm{AOR}$, Adjusted odds ratio, adjusted for the influence of all other variables in the model; $\mathrm{Cl}$, confidence interval.

substantial given that the recall period was limited to a single event (see table 1).

\section{Limitations}

Findings are limited by the validity of retrospective self-report. Also, the use of a convenience sample limits the generalisability. Finally, it should be noted that although many of the men were married, they were all using condoms and these observed errors/ problems may have a bearing on continued use as well as condom failure. Whether these men were using condoms to

\section{Key messages}

- Men who used condoms unilaterally were more likely to report breakage. This association has not previously been reported in the literature. One implication of the finding is that women who are also motivated to use condoms may indeed guide men in the correct application and use of condoms to the degree that breakage is averted.

- Men who used condoms unilaterally were more likely to report early removal of condoms and slippage during withdrawal. Although qualitative follow-up research is important, the former finding may be a consequence of their partner's lack of interest in using condoms. The latter finding may stem from a lack of female assistance in holding on to the rim during withdrawal (perhaps based on their lack of investment in condom use).

- As a consequence of controlling for men's level of experience using condoms the study found those reporting "quite a lot" of experience made substantially fewer errors and experienced fewer problems. An effective intervention strategy may thus be to "target" education to refine the quality of condom use to men acknowledging limited experience with this behaviour. prevent pregnancy versus STI was not assessed; however, it is important to note that the "last time" a condom was used may not have been with the spouse (implicating the prevention of STI acquisition as a possible motive for use). The findings are thus also limited on the basis of the generic assessment of condom use errors and problems rather than an assessment stratified by casual versus main partner types.

\section{CONCLUSIONS}

Findings suggest that female involvement in the decision to use condoms for penile-vaginal sex may be partly protective against some condom errors/problems. Men's self-reported level of experience using condoms may be a useful indicator of the need for education designed to promote the correct use of condoms. Education programmes may benefit men and women if they encourage women to become involved in condom use decisions.

Funding: Support for this project was provided by the Canada Research Chair in Social Justice and Sexual Health at the University of Windsor, and the Rural Center for AIDS/ STD Prevention and The Kinsey Institute for Research in Sex, Gender, and Reproduction at Indiana University.

Competing interests: None declared.

Contributions: RC participated in the conception of the study, analysed and interpreted the data, drafted the manuscript, and finalised the manuscript. RM acquired funding for the study, conceived the methodology for data collection, implemented the study, cleaned the dataset, and provided guidance to RC in the conception of the study and drafting/revisions of the manuscript. WLY, SAS and CAG all participated in the conception of the study, analysis and interpretation of the data, drafting/revision of the manuscript.

\section{REFERENCES}

1. Holmes KK, Levine R, Weaver M. Effectiveness of condoms in preventing sexually transmitted infections. Bulletin WHO 2004;82:454-61.

2. Centers for Disease Control and Prevention. Sexually transmitted diseases treatment guidelines 2002. MMWR Morb Mortal Wkly Rep 2002;51:1-60.

3. Cates W Jr. The NIH condom report: the glass is $90 \%$ full. Fam Plann Perspect 2001;33:231-3 
4. Crosby RA, Yarber WL, Sanders SA, et al. Condom discomfort and associated problems with their use among university students. Am J College Health 2005; 54:143-8.

5. Crosby RA, Yarber WL, Sanders SA, et al. Men with broken condoms: who and why? Sex Transm Infect 2007;83:71-5.

6. Spruyt A, Steiner MJ, Joanis C, et al. Identifying condom users at risk for breakage and slippage: findings from three international sites. Am J Public Health 1998; 88:239-44.

7. Grimley DM, Annang L, Houser $S$, et al. Prevalence of condom use errors among STD clinic patients. Am J Health Behav 2005;29:324-30.

8. Warner L, Clay-Warner J, Boles J, et al. Assessing condom use practices: implications for evaluating method and user effectivness. Sex Transm Dis 1998:25:273-7.

9. Crosby RA, Sanders S, Yarber WL, et al. Condom use errors and problems among college men. Sex Transm Dis 2002;29:552-7.

10. Sanders SA, Graham CA, Yarber WL, et al. Condom use errors and problems among young women who apply put condoms on their male partners. J Am Med Women's Assoc 2003;58:95-8.
11. Yarber WL, Graham CA, Sanders SA, et al. Correlates of condom breakage and slippage among university undergraduates. Int J STD AIDS 2004;15:467-72.

12. Crosby RA, Sanders SA, Yarber WL, et al. Condom use errors and problems: a neglected aspect of studies assessing condom effectiveness. Am J Prev Med 2003;24:367-70.

13. Crosby RA, Salazar LF, DiClemente RJ, et al. Accounting for failures may improve precision: evidence supporting improved validity of self-reported condom use. Sex Transm Dis 2005;32:513-15.

14. Richters J, Donovan B, Gerofi J. How often do condoms break or slip off in use? Int J STD AIDS 1993;4:90-4.

15. Macaluso M, Kelaghan J, Artz L, et al. Mechanical failure of the latex condom in a cohort of women at high STD risk. Sex Transm Dis 1999;26:450-7.

16. Essien EJ, Ross MW, Fernandez-Esquer ME, et al. Reported condom use and condom use difficulties in street outreach samples of men of four racial and ethnic backgrounds. Int J STD AIDS 2005;16:739-43.

17. Civic D, Scholes D, Ichikawa L, et al. Ineffective use of condoms among young women in managed care. AIDS Care 2002;14:779-88.

\section{Access a vast information database with Toll-Free linking}

"Toll-free" linking gives you immediate access to the full text of many of the cited articles in a paper's reference list-FOR FREE. With the support of HighWire's vast journal catalogue, a huge reference library is now open to you. If HighWire hosts the journal, you can view the full text of the referenced article, completely free of charge by following the Free Full Text links in the references. 


\section{STI}

\section{Two heads are better than one: the association between condom decision-making and condom use errors and problems}

R Crosby, R Milhausen, S A Sanders, et al.

Sex Transm Infect 2008 84: 198-201

doi: $10.1136 /$ sti.2007.027755

Updated information and services can be found at:

http://sti.bmj.com/content/84/3/198.full.html

\section{These include:}

References This article cites 17 articles, 4 of which can be accessed free at: http://sti.bmj.com/content/84/3/198.full.html\#ref-list-1

Article cited in:

http://sti.bmj.com/content/84/3/198.full.html\#related-urls

Email alerting Receive free email alerts when new articles cite this article. Sign up in service the box at the top right corner of the online article.

Topic Articles on similar topics can be found in the following collections Collections

Reproductive medicine (27658 articles)

Condoms (224 articles)

Notes

To request permissions go to:

http://group.bmj.com/group/rights-licensing/permissions

To order reprints go to:

http://journals.bmj.com/cgi/reprintform

To subscribe to BMJ go to:

http://group.bmj.com/subscribe/ 